\title{
Sex, linkage disequilibrium and patterns of parasitism in three species of cyclically parthenogenetic Daphnia (Cladocera: Crustacea)
}

\author{
TOM J. LITTLE* $+\uparrow \&$ DIETER EBERT† \\ $\dagger$ Institut für Zoologie, Universität Basel, CH-4051 Basel, Switzerland and $\ddagger$ Max-Planck Institut für Limnologie, \\ August-Thienemann-Straße 2, 24306 Plön, Plön, Germany
}

\begin{abstract}
To gain insight into genetic variation for resistance to parasites, this study assayed clonal variation in cyclically parthenogenetic Daphnia magna with respect to parasitic infection. Samples were collected from natural populations, and the allozyme phenotypes of infected hosts were compared to those of uninfected hosts. Differences between the clonal composition of the infected and uninfected class were evident in only two of 16 populations examined. This result stands in contrast to a study of species in the $D$. pulex and D. longispina species complexes, where clonal variation for infection was found in 12 of 25 populations (Little \& Ebert, 1999). Considering all populations from both studies, associations between host genotype and infection were typically evident only in populations that showed low genotypic diversity and evidence of genetic disequilibria, with D. magna showing the least amount of disequilibria. This pattern is compatible with at least two possibly overlapping hypotheses. First, it may be that those populations lacking clonal variation for infection experienced weaker parasitemediated selection. We can not rule out variation in selection pressure as an explanation, but found no evidence that the prevalence or intensity of parasitism differed either among species, or between those populations which showed clonal variation for infection and those that did not. Second, it could be that some populations, especially those of D. magna, have more frequent sexual recruitment than others. Sexual recombination breaks up gene combinations which are in linkage disequilibrium, and our method to detect clonal variation for resistance relies on linkage between genetic markers (allozymes) and resistance loci. Past work on Daphnia has shown that the level of sexual recruitment (which is in turn mediated by habitat permanency) is indeed commonly linked to the occurrence of genetic disequilibria. Our results may thus underestimate the prevalence of clonal variation for infection (especially for D. magna), because most of the populations analysed appeared to have high levels of sexual recruitment and therefore lacked the linkage disequilibrium that underlies associations between allozymes and susceptibility.
\end{abstract}

Keywords: clone, linkage disequilibrium, parasite, parthenogenesis, resistance, selection, sexual reproduction.

\section{Introduction}

Cycles of apomixis and sexuality in cyclically parthenogenetic taxa provide an opportunity to identify prevalent agents of natural selection in the wild (e.g. Hebert, 1974a,b; Lynch, 1983; Carvalho \& Crisp, 1987;

\footnotetext{
*Correspondence and present address: Institute for Cell, Animal and Population Biology, University of Edinburgh, Kings Buildings, West Mains Rd, Edinburgh, EH9 3JT, Scotland, U.K.

E-mail: tom.little@ed.ac.uk
}

(C) 2000 The Genetical Society of Great Britain.
Roy \& Bierzychudek, 1993; Roy, 1993; Little \& Ebert, 1999). During phases of clonal reproduction, selection can efficiently erode genotypic variation such that populations are reduced to a relatively small number of multilocus genotypes (clones) which may differ markedly in their ecological attributes. One useful consequence of clonal selection is that populations are in linkage disequilibrium, and as a result, ecologically differentiated clones may also differ at genetic marker loci such as allozymes. The identification of ecologically differentiated clones with simple genetic markers greatly 
facilities large-scale analyses of both the fitness differences among genotypes (the potential for natural selection) and temporal changes of these genotypes (an indication of natural selection in action).

Assuming allozyme variants to be selectively neutral, or at least not directly involved in the fitness traits being studied, nonrandom associations (linkage disequilibrium) between fitness-related loci and allozymes in clonal taxa likely arise through the hitchhiking of allozymes with gene complexes that are under selection. Thus, in the absence of recombination, small amounts of linkage disequilibrium are amplified. A single bout of sexual reproduction will, however, reduce linkage disequilibrium and re-establish a larger range of multilocus genotypes, which are then exposed to selection in the next phase of apomictic reproduction. Thus, in populations engaging in periodic sex, patterns of genotypic variation are tightly linked to the frequency of sexual recruitment (e.g. Hebert, 1974a,b; Lynch \& Deng, 1994). Consequently, the utility of using allozymes to identify clonal differences for fitness-related traits will depend on both the length of the apomictic period and the strength of selection, because the likelihood of detecting gametic phase imbalance rises as clone numbers decline through clonal selection. When sexual recruitment is common, populations will tend towards genetic equilibria and fitness differences among allozymic clones are likely to be subtle. Such a relationship between sexual recruitment, linkage disequilibrium and fitness differences among clones has been demonstrated in cyclically parthenogenetic rotifers (King, 1972), aphids (Fraser, 1972) and Daphnia (Hebert \& Ward, 1976).

A number of studies have exploited the occurrence of linkage between allozymes and loci under selection in clonal taxa to search for genetic variation for resistance to parasites (Parker, 1988; Roy \& Bierzychudek, 1993; Roy, 1993; Chaboudez \& Burdon, 1995; Dybdahl \& Lively, 1995; Little \& Ebert, 1999). One motivation for such studies is the notion that parasites and pathogens are potent agents of fluctuating selection that might be responsible for the maintenance of genetic diversity in their hosts (Haldane, 1949; Levin, 1975; Jaenike, 1978; Hamilton, 1980). This hypothesis assumes sufficiently high parasite-mediated fitness reductions, and that host genotypes differ in susceptibility. Studies of a variety of parasite-host systems (e.g. Burdon \& Jarosz, 1991; Jarosz \& Burdon, 1991; Thompson \& Burdon, 1992; Grosholz, 1994; Webster \& Woolhouse, 1998; Little \& Ebert, 1999) have shown that these criteria are generally met, although it remains unresolved whether parasitism is the pervasive evolutionary force suggested by theoretical work (e.g. Frank, 1996a; Hamilton et al., 1990; Hamilton, 1993; Parker, 1994, 1996; Frank, 1996b).
Investigations of the parasites of cyclically parthenogenetic Daphnia have, almost without exception, shown that parasites reduce the fecundity and/or survival of infected individuals (Little \& Ebert, 1999; Stirnadel \& Ebert, 1997). To assess genetic variation for resistance in Daphnia, Little \& Ebert (1999) examined 25 populations, largely involving pond-dwelling species in the $D$. pulex and D. longispina groups, and documented clonal variation for infection in 12 of these. The present study examined clonal variation for infection in populations of Daphnia magna, a species which was barely represented in Little \& Ebert (1999). Combined results from both studies indicated large among-population and species-specific differences in population genetic structuring which were linked to the occurrence of clonal variation for infection. We therefore analysed the combined data set to (1) gain insight into the consequences of long-term apomixis for the genetic structure of host populations in relation to parasite infection, and (2) use this knowledge to assess the generality of resistance-variation in natural Daphnia populations.

\section{Methods}

Between May and October of 1997, Daphnia magna were collected once from each of 26 ponds in northern Germany near Plön by passing a $\sim 300 \mu \mathrm{m}$ mesh net through the water near shore. Collections were immediately cooled on ice and maintained at low temperatures until analysed within one day. To analyse the genetic composition of hosts in relation to parasite infection, the methods outlined in Little \& Ebert (1999) were used. Briefly, each sample was first screened for the number of parasite species which were both common enough for analysis and visible without host dissection. Each parasite species was treated separately and the genetic profile of infected hosts was compared to that of uninfected hosts. We also determined the genetic profile of a randomly selected group of individuals. In total then, from each population sample, we collected at least three subsamples: random, healthy, and parasitized (one subsample for each parasite species, from 24 to 146 individuals per subsample, mean $=78$ ) which were genetically characterized with cellulose acetate electrophoresis (for methodological details see Hebert \& Beaton, 1993). Initially, 12 individuals from each of six populations were screened for variation at 13 enzyme loci known to often be polymorphic in freshwater crustaceans. These enzymes were: aldehyde oxidase (AO) (EC 1.2.1), amylase (AMY) (EC 3.2.1.1), arginine phosphokinase (APK-1) (EC 2.7.2), aspartate aminotransferase (AAT) (EC 2.6.1.1), fumarate hydratase (FUM) (EC 4.2.1.2), glucophosphate isomerase (GPI) (EC 5.1.9), isocitrate dehydrogenase (IDH) (EC 
1.1.1.42), lactate dehydrogenase (LDH) (EC 1.1.1.27), malic enzyme (ME) (EC 1.1.1. 40), malic dehydrogenase (MDH) (EC 1.1.1.37), mannose phosphate isomerase (MPI) (EC 5.1.8), peptidase-C (phenyl-proline) (PEP-C) and phosphoglucomutase (PGM) (EC 2.7.5.1). Following the initial screening, populations were analysed for variation at only those loci found to be polymorphic.

\section{Analysis}

Allozyme bands with unique electrophoretic mobility were assumed to correspond to unique alleles, and distinct multilocus genotypes were termed clones. We assumed that individuals sharing the same allozyme phenotype may possess amino acid substitutions that do not result in detectable mobility differences, or they might differ at loci not assayed. Thus, an allozymic 'clone' probably represents a clonal group whose members happen to share the same allozyme phenotype.

Significant differences between the clonal composition of the parasitized and healthy class in each sample were determined with a contingency table and Fisher's Exact Test (SAS Institute Inc, 1990). When a significant difference was detected, further Exact Tests were performed on particular clones to determine which ones were 'over parasitized' and which were 'under-parasitized'. In addition, to quantify the degree to which the parasitized class of clones differed from that of the healthy class, we calculated the averaged Euclidean distance (Krebs, 1989) separating the clonal composition of these two groups in each population.

Using the computer program BIOSYS-I (Swofford \& Selander, 1988), with a locus considered polymorphic if the frequency of the common allele did not exceed 0.99 , we determined heterozygosity, percent polymorphic loci, the number of alleles per locus, the fixation index $(F)$, and conformance to Hardy-Weinberg (H.W.) equilibrium for the random sample from each population. Conformance to H.W. equilibrium was determined by calculating exact significance probabilities (EXACTP option in BIOSYS-I). Also using Fisher's Exact Test, we determined whether pairs of genotypes from different loci were found together more often than would be expected by chance alone (i.e. genotypic linkage disequilibrium). When we performed multiple tests for H.W. equilibrium or genotypic disequilibrium within single populations, we adjusted significance levels with a sequential Bonferroni correction (Rice, 1989).

We calculated two other measures of diversity. First, clonal diversity in the random sample of each population was estimated using Simpson's (1949) index of diversity modified for finite populations (Pielou, 1969).
Second, we calculated the genotypic diversity ratio (GDR) (Hoffmann, 1986; Innes et al., 1986). The GDR is the observed divided by the expected number of unique multilocus genotypes in a population. The observed value is simply a direct count of the number of clones in a population. The expected value was calculated using a Monte-Carlo simulation which estimated the genotypic diversity that would be expected in a sexually reproducing, randomly outcrossing population with allelic frequencies identical to those observed in each study population. The GDR is influenced by both the strength of selection and the frequency of sexual recruitment in a population. A GDR of approximately 1.0 indicates that the population has the full range of unique multilocus genotypes expected under sexual reproduction and no selection on either the marker genes or at loci linked to the marker genes. GDR values significantly less then 1.0 suggest that genotypic diversity has been culled, most likely due to selection at loci linked to the marker genes. Genotypic diversity could also be lost through random genetic drift, but this is unlikely to be common given the huge population sizes typical of Daphnia.

\section{Results}

\section{Patterns of parasitism and genetic diversity in Daphnia magna populations}

Parasite prevalences were sufficiently high (i.e. so that at least 24 infected animals could be electrophoresed) for analysis in 16 of 26 Daphnia magna populations examined. Four of these 16 populations were infected with two parasite species, while two populations were infected with three parasite species, giving a total of 24 samples, each representing one unique parasite specieshost species combination (Table 1). Parasite prevalences ranged from less than $1 \%$ to $43 \%$, averaging $11.3 \%$. In total we found 6 different parasite species which included 3 microsporidians (Thelohania sp. which infects the epidermis, and two undescribed species which infect the fat cells and ovaries), two bacteria (Pasteuria ramosa, which grows in the haemolymph, and White Bacterial Disease, a parasite of the fat cells), and one fungus (Saprolegniaceae) which consumes parthenogenetic eggs in the brood chamber.

In two of the 24 samples the clonal composition of the healthy class of hosts differed significantly from that of parasitized hosts (Tables 1,2). These significant associations were evident the first time the populations were sampled. Applying a Bonferonni correction gives a cutoff $P$-value of 0.0031 , at which point neither of these two populations show significant clonal variation for infection. Supporting the likelihood that these two results are 
Table 1 Population genetic data for 16 populations of Daphnia magna representing 24 unique parasite species-host species combinations. All parameters, except for the last column, were based on a random population sample. p.p.m. is percent polymorphic loci. Clonal diversity is based on the Simpson diversity index. $F$ is the fixation index. H.W. denotes a Hardy-Weinberg disturbance $(P<0.05)$ at $X$ of $Y$ polymorphic loci, while L.D. denotes significant $(P<0.05)$ linkage between $X$ of $Y$ possible two-locus genotype combinations. $P$ indicates the significance of tests to determine if the healthy class of individuals had a clonal composition which differed from that of the random class. See Table 2 for details of the two populations which showed a significant difference at at least the $P=0.05$ level (corrected for multiple tests the $P$-value is 0.0031 ; no populations showed significant differences at this level)

\begin{tabular}{|c|c|c|c|c|c|c|c|c|c|c|c|}
\hline Sample & Parasite & $\begin{array}{c}\text { Sampling } \\
\text { date }(\mathrm{D} / \mathrm{M})\end{array}$ & $\begin{array}{c}\text { Parasite } \\
\text { prevalence }\end{array}$ & p.p.m. & $\begin{array}{l}\text { Clonal } \\
\text { diversity }\end{array}$ & $\begin{array}{l}\text { Het } \\
\text { (obs.) }\end{array}$ & $\begin{array}{l}\text { Het } \\
\text { (exp.) }\end{array}$ & $F$ & H.W. & L.D. & $P$ \\
\hline NG1 & $\begin{array}{l}\text { White Bacterial Disease } \\
\text { Unknown microsporidian } 1\end{array}$ & $10 / 5$ & $\begin{array}{l}0.20 \\
0.04\end{array}$ & 0.23 & 0.99 & 0.171 & 0.180 & 0.04 & 0 of 4 & 0 of 6 & $\begin{array}{l}\text { n.s. } \\
\text { n.s. }\end{array}$ \\
\hline NG2 & Pasteuria ramosa & $26 / 8$ & 0.05 & 0.15 & 0.81 & 0.089 & 0.074 & -0.20 & 1 of 2 & 0 of 1 & $<0.01$ \\
\hline NG3 & Pasteuria ramosa & $2 / 9$ & 0.17 & 0.15 & 0.90 & 0.084 & 0.080 & -0.07 & 0 of 2 & 0 of 1 & $<0.05$ \\
\hline NG4 & $\begin{array}{l}\text { Unknown microsporidian } 1 \\
\text { Saprolegnia sp. (Saprolegniaceae) }\end{array}$ & $27 / 5$ & $\begin{array}{l}0.23 \\
0.02\end{array}$ & 0.15 & 0.88 & 0.078 & 0.074 & -0.09 & 0 of 2 & 0 of 1 & $\begin{array}{l}\text { n.s. } \\
\text { n.s. }\end{array}$ \\
\hline NG5 & Unknown microsporidian 1 & $12 / 6$ & 0.10 & 0.23 & 0.79 & 0.078 & 0.069 & -0.11 & 0 of 3 & 3 of 3 & n.s. \\
\hline NG6 & $\begin{array}{l}\text { Pasteuria ramosa } \\
\text { Unknown microsporidian } 1\end{array}$ & $6 / 5$ & $\begin{array}{l}0.24 \\
0.02\end{array}$ & 0.38 & 0.99 & 0.185 & 0.191 & 0.02 & 0 of 5 & 0 of 6 & $\begin{array}{l}\text { n.s. } \\
\text { n.s. }\end{array}$ \\
\hline NG7 & $\begin{array}{l}\text { Thelohania sp. (Microsporidia) } \\
\text { Unknown microsporidian } 1\end{array}$ & $26 / 6$ & $\begin{array}{l}0.06 \\
0.02\end{array}$ & 0.23 & 0.89 & 0.089 & 0.089 & -0.02 & 0 of 3 & 0 of 1 & $\begin{array}{l}\text { n.s. } \\
\text { n.s. }\end{array}$ \\
\hline NG8 & Unknown microsporidian 1 & $26 / 6$ & 0.43 & 0.23 & 0.97 & 0.108 & 0.113 & 0.03 & 0 of 3 & 0 of 3 & n.s. \\
\hline NG9 & $\begin{array}{l}\text { Pasteuria ramosa } \\
\text { Unknown microsporidian } 2 \\
\text { White Bacterial Disease }\end{array}$ & $10 / 5$ & $\begin{array}{l}0.07 \\
0.01 \\
0.09\end{array}$ & 0.31 & 0.94 & 0.085 & 0.084 & -0.01 & 0 of 4 & 0 of 6 & $\begin{array}{l}\text { n.s. } \\
\text { n.s. } \\
\text { n.s. }\end{array}$ \\
\hline NG10 & Pasteuria ramosa & $2 / 7$ & 0.13 & 0.23 & 0.97 & 0.135 & 0.126 & -0.09 & 0 of 3 & 0 of 3 & n.s. \\
\hline NG11 & Thelohania sp. (Microsporidia) & $2 / 7$ & 0.37 & 0.23 & 0.94 & 0.135 & 0.123 & -0.28 & 2 of 3 & 3 of 3 & n.s. \\
\hline NG12 & Pasteuria ramosa & $14 / 8$ & 0.03 & 0.38 & 0.95 & 0.131 & 0.143 & 0.05 & 0 of 5 & 0 of 3 & n.s. \\
\hline NG13 & Unknown microsporidian 2 & $28 / 8$ & 0.01 & 0.38 & 0.96 & 0.111 & 0.119 & 0.01 & 0 of 5 & 0 of 10 & n.s. \\
\hline NG14 & $\begin{array}{l}\text { Pasteuria ramosa } \\
\text { Unknown microsporidian } 1 \\
\text { Unknown microsporidian } 2\end{array}$ & $10 / 7$ & $\begin{array}{l}0.24 \\
0.11 \\
0.03\end{array}$ & 0.15 & 0.84 & 0.071 & 0.063 & 0.08 & 0 of 2 & 0 of 1 & $\begin{array}{l}\text { n.s. } \\
\text { n.s. } \\
\text { n.s. }\end{array}$ \\
\hline NG15 & Unknown microsporidian 2 & $17 / 7$ & 0.01 & 0.15 & 0.79 & 0.059 & 0.060 & -0.05 & 0 of 2 & 0 of 1 & n.s. \\
\hline NG16 & Pasteuria ramosa & $2 / 9$ & 0.11 & 0.15 & 0.97 & 0.121 & 0.116 & -0.06 & 0 of 3 & 0 of 3 & n.s. \\
\hline Mean & & & 0.11 & 0.24 & 0.85 & 0.10 & 0.10 & -0.05 & 3 of 51 & 6 of 52 & \\
\hline
\end{tabular}


Table 2 Clonal frequencies and allozyme phenotypes in two populations in which the clonal composition differed significantly between the healthy and parasitized classes based on a contingency table analysis and Fisher's Exact test (see Table 1). P-clone is the significance of Exact Tests applied to individual clones

\begin{tabular}{|c|c|c|c|c|c|c|c|c|c|c|c|}
\hline \multirow[b]{2}{*}{ Population } & \multirow[b]{2}{*}{ Clone } & \multicolumn{2}{|c|}{ Allozyme phenotype } & \multirow{2}{*}{\multicolumn{2}{|c|}{ Random }} & \multirow[b]{2}{*}{$\%$} & \multirow[b]{2}{*}{ Healthy } & \multirow[b]{2}{*}{$\%$} & \multirow[b]{2}{*}{ Infected } & \multirow[b]{2}{*}{$\%$} & \multirow[b]{2}{*}{$P$-clone } \\
\hline & & MPI & GOT & & & & & & & & \\
\hline \multirow[t]{10}{*}{ NG2 } & 1 & aa & $\mathrm{bb}$ & & 1 & 0.01 & 1 & 0.01 & 4 & 0.03 & \\
\hline & 2 & aa & $\mathrm{bc}$ & & 3 & 0.03 & 4 & 0.03 & 9 & 0.06 & \\
\hline & 3 & $\mathrm{ac}$ & $\mathrm{bb}$ & & 11 & 0.10 & 12 & 0.09 & 13 & 0.09 & \\
\hline & 4 & ac & $\mathrm{bc}$ & & 25 & 0.23 & 34 & 0.26 & 25 & 0.18 & \\
\hline & 5 & $\mathrm{ac}$ & $\mathrm{cc}$ & & 18 & 0.16 & 20 & 0.16 & 17 & 0.12 & \\
\hline & 6 & $\mathrm{cc}$ & $\mathrm{bb}$ & & 3 & 0.03 & 5 & 0.04 & 23 & 0.17 & $P<0.001$ \\
\hline & 7 & $\mathrm{cc}$ & $b c$ & & 34 & 0.31 & 36 & 0.28 & 28 & 0.20 & \\
\hline & 8 & $\mathrm{cc}$ & $\mathrm{cc}$ & & 15 & 0.14 & 17 & 0.13 & 9 & 0.06 & \\
\hline & 9 & aa & $\mathrm{cc}$ & & 0 & 0.00 & 0 & 0.00 & 11 & 0.08 & $P<0.01$ \\
\hline & & & & $n:$ & 110 & 1.00 & 129 & 1.00 & 139 & 1.00 & \\
\hline \multirow[t]{10}{*}{ NG3 } & 1 & $\mathrm{cc}$ & $\mathrm{cc}$ & & 2 & 0.03 & 3 & 0.02 & 4 & 0.03 & \\
\hline & 2 & $\mathrm{cc}$ & $\mathrm{bc}$ & & 3 & 0.04 & 6 & 0.04 & 11 & 0.08 & \\
\hline & 3 & $\mathrm{cc}$ & $\mathrm{bb}$ & & 4 & 0.06 & 16 & 0.11 & 5 & 0.04 & $P<0.05$ \\
\hline & 4 & $\mathrm{bc}$ & $\mathrm{cc}$ & & 6 & 0.09 & 8 & 0.06 & 8 & 0.06 & \\
\hline & 5 & $b c$ & $\mathrm{bc}$ & & 15 & 0.22 & 37 & 0.26 & 31 & 0.23 & \\
\hline & 6 & $\mathrm{bc}$ & $\mathrm{bb}$ & & 14 & 0.21 & 32 & 0.23 & 27 & 0.20 & \\
\hline & 7 & bb & $\mathrm{cc}$ & & 1 & 0.01 & 4 & 0.03 & 0 & 0.00 & \\
\hline & 8 & $\mathrm{bb}$ & $\mathrm{bc}$ & & 15 & 0.22 & 16 & 0.11 & 32 & 0.24 & $P<0.01$ \\
\hline & 9 & $\mathrm{bb}$ & $\mathrm{bb}$ & & 7 & 0.10 & 20 & 0.14 & 15 & 0.11 & \\
\hline & & & & $n:$ & 67 & 1.00 & 142 & 1.00 & 133 & 1.00 & \\
\hline
\end{tabular}

only chance deviations is the observation that, for both cases, this observation was not repeatable, i.e. the clonal composition of the healthy and parasitized hosts did not differ significantly when the populations were resampled one week later. Eleven of the other populations, none of which showed significant clonal associations with parasitism when first sampled, were each analysed from two to six additional times over the course of the summer. No associations between host clones and parasitism were detected in these later samples, nor did any of these populations stray from genetic equilibria.

\section{Comparisons among species and populations}

We combined the present result with that of Little \& Ebert (1999) to compare the population genetic characteristics of those populations which showed clonal variation for infection to those that did not, as well as to make comparisons among species. For the combined data set, duplicate samples from the same population were discarded as follows: for cases where one population had multiple parasite species, we considered only the dominant parasite, whereas for populations where we took multiple samples of the same parasite-host combination over time, we include only the first sample. The combined data set includes 17 D. magna populations, 15 populations from the $D$. pulex species complex, and 8 populations from the $D$. longispina species complex. Of these, 14 populations showed clonal variation for infection and 26 populations did not. Table 3 summarizes the population genetic characteristics for all Daphnia populations and species. Comparison of these characteristics among the three species were performed with an analysis of variance (ANOVA, SAS Procedure GLM (SAS, 1990)), except for cases where the data were not normally distributed when a Kruskal-Wallis 3 group test was then used. For comparisons between populations that showed clonal variation for infection and those that did not, Mann-Whitney $U$-tests were performed.

Differences among species were detected only for clonal diversity $(F=4.99$, d.f. $=2, P<0.012$, residuals normally distributed), with $D$. magna populations having the highest levels of clonal diversity, and species in the $D$. pulex complex having the lowest clonal diversity (Table 3). Populations with significant clonal variation for infection had lower clonal diversity $(U=94$, $P=0.012)$, a lower average GDR $(U=91, P=0.0099)$, and a lower, more negative, fixation index $(U=100.5$, $P=0.041)$ than those populations that showed no clonal variation for infection (Table 3). Populations with clonal variation for infection were more likely to show both linkage disequilibrium (18 of $43[=41.8 \%$ ] tests 
Table 3 Summary of genetic characteristics ( \pm SE in parenthesis) in relation to the incidence of parasitism in 40 populations representing three species of Daphnia. Asterisks represent significant differences $\left({ }^{*} P<0.05,{ }^{*} P<0.01\right)$ either among species or between those populations that showed clonal variation for infection and those that did not

\begin{tabular}{|c|c|c|c|c|c|}
\hline & $\begin{array}{c}\text { D. magna } \\
n=17 \\
\text { populations }\end{array}$ & $\begin{array}{c}\text { D. pulex } \\
n=15 \\
\text { populations }\end{array}$ & $\begin{array}{l}\text { D. longispina } \\
n=8 \\
\text { populations }\end{array}$ & $\begin{array}{c}\text { Showing clonal } \\
\text { variation for infection } \\
n=14 \text { populations }\end{array}$ & $\begin{array}{l}\text { Not showing clonal } \\
\text { variation for } \\
\text { infection } n=26 \\
\text { populations }\end{array}$ \\
\hline Parasite prevalence & $0.12(0.024)$ & $0.14(0.043)$ & $0.09(0.035)$ & $0.12(0.023)$ & $0.13(0.028)$ \\
\hline Percent polymorphic loci & $0.24(0.021)$ & $0.23(0.028)$ & $0.27(0.026)$ & $0.24(0.027)$ & $0.25(0.017)$ \\
\hline Alleles/locus & $2.2(0.055)$ & $2.1(0.056)$ & $2.5(0.155)$ & $2.1(0.074)$ & $2.3(0.65)$ \\
\hline Heterozygosity (expected) & $0.11(0.009)$ & $0.09(0.013)$ & $0.12(0.080)$ & $0.09(0.014)$ & $0.11(0.044)$ \\
\hline \multirow[t]{2}{*}{ Heterozygosity (observed) } & $0.11(0.009)$ & $0.09(0.020)$ & $0.13(0.020)$ & $0.11(0.021)$ & $0.11(0.008)$ \\
\hline & & $*$ & & \multicolumn{2}{|l|}{$*$} \\
\hline \multirow[t]{2}{*}{ Clonal Diversity } & $0.91(0.017)$ & $0.61(0.076)$ & $0.82(0.042)$ & $0.63(0.081)$ & $0.86(0.026)$ \\
\hline & & & & \multicolumn{2}{|l|}{$*$} \\
\hline \multirow[t]{2}{*}{ Fixation Index $(F)$} & $0.05(0.023)$ & $-0.05(0.088)$ & $-0.03(0.049)$ & $-0.14(0.071)$ & $0.008(0.031)$ \\
\hline & & & & \multicolumn{2}{|c|}{$* *$} \\
\hline $\begin{array}{l}\text { Genotypic diversity } \\
\text { ratio (GDR) }\end{array}$ & $0.89(0.026)$ & $0.77(0.069)$ & $0.90(0.087)$ & $0.73(0.073)$ & $0.91(0.028)$ \\
\hline $\begin{array}{l}\text { Percent of populations } \\
\text { showing clonal variation } \\
\text { for infection }\end{array}$ & 11.7 & 66.7 & 25.0 & 100.0 & 0.0 \\
\hline
\end{tabular}

significant vs. 11 of $125[=8.8 \%]$ ) for populations without such clonal variation. Populations with clonal variation for infection were also more likely to show Hardy-Weinberg (H.W.) deviations (eight of 36 $[=22.2 \%]$ tests significant vs. seven of $98[7.1 \%]$. As indicated by the negative sign of the fixation index, H.W. disturbances towards heterozygote excess were more severe in those populations where significant clonal variation for infection was evident. Heterozygosities, the percentage of polymorphic loci, the average number of alleles per locus, and parasite prevalences were also compared, but none of these measures differed among species or between populations which showed clonal variation for infection and those that did not.

We used the following additional method to investigate the relationship between population genetic characteristics and the occurrence of clonal variation for infection. With an analysis of covariance (SAS procedure GLM), we tested for a relationship between the genotypic diversity ratio (GDR), species, and the averaged Euclidean distance separating the clonal composition of the healthy and infected clones in each population (a measure of the strength of clonal variation for infection, see methods). The GDR showed a strong relationship to the Euclidean distance index (Type III $\mathrm{SS}=0.6811, \quad F=18.13, \quad$ d.f. $=1, \quad P<0.0001$; error $\mathrm{MS}=0.0376$, d.f. $=36$ ), with increasing GDR corresponding to smaller distances separating the clonal composition of healthy and infected hosts (Fig. 1). Species effects were insignificant in this analysis (Type III SS $=0.0267, F=0.36$, d.f. $=2, P=0.70$ ). We repeated this analysis with the data transformed to be more evenly distributed - Euclidean distances were log transformed, whereas GDR values were squared. Analysis on the transformed data also indicated a significant relationship between the GDR and the Euclidean distance index (Type III SS $=0.6011, \mathrm{MS}=0.6011$, $F=7.4$, d.f. $=1, P<0.01$ ). Separate analysis of the relationship between the GDR and Euclidean distance index for each species revealed a significant relationship for $D$. pulex $(P=0.007)$, borderline significance for $D$. longispina $(P=0.51)$ and no relationship for D. magna $(P=0.67)$.

\section{Discussion}

Under the assumption that periods of clonal selection in Daphnia populations might, in some cases, result in 


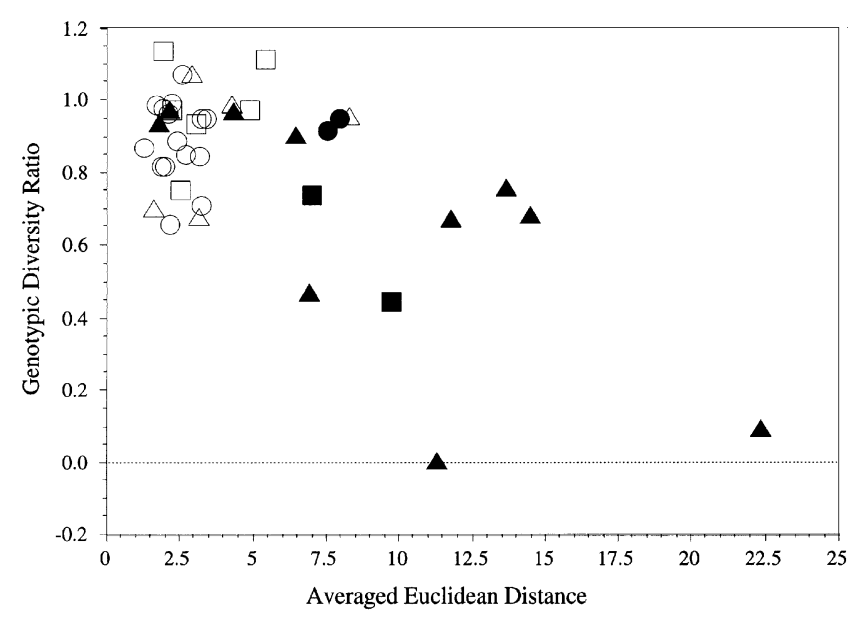

Fig. 1 Scattergram depicting the relationship between the genotypic diversity ratio (GDR - a measure influenced by selection and the amount of sexual recruitment within a population) and the averaged Euclidean distance separating the genetic composition of healthy hosts from that of infected hosts (a measure of the strength of clonal variation for infection within a population) in each of 40 Daphnia populations. Circles represent D. magna, squares D. longispina, triangles $D$. pulex. Open symbols represent those populations which showed no significant difference between the genetic composition of healthy hosts and that of infected hosts, whereas filled symbols represent those populations which showed a significant difference.

associations between marker genes and resistance loci, this study searched for genetic variation for infection by using allozymes to determine if infected individuals within a population have a different clonal composition from that of healthy individuals. Associations between infection and host genotype could reflect either genetic variation for resistance or a nonrandom spatial arrangement of both host genotypes and parasites within ponds. In the short term, either factor could lead to parasitemediated gene-frequency changes, and thus the occurrence of clonal variation for infection reveals the potential for natural selection by parasites. Sixteen natural populations of Daphnia magna infected with a variety of parasite species were examined, and clonal variation for infection was detected in just two populations. This result stands in contrast to a previous study (Little \& Ebert, 1999), primarily involving pond-dwelling species in the $D$. pulex and D. longispina species complexes, where clonal variation for infection was found in half of the populations examined. Methodologically, the two studies did not differ in any significant way. We therefore combined the data from both studies (40 populations in total) to address the variation among both populations and species regarding the occur- rence of associations between allozymes and infection (summarized in Table 3).

Comparisons among species, as well as between those populations that showed clonal variation for infection and those that did not, revealed no differences in basal genetic diversity, i.e. there were no significant differences in percent polymorphic loci, average number of alleles per locus or expected heterozygosity. However, significant differences were evident for measures of genotypic variability, as indicated by the observation that genetic disequilibria were more common in populations showing clonal variation for infection. This pattern is quantified by the fixation index and the genotypic diversity ratio (GDR). These two measures describe how closely a population approximates to the genotypic architecture expected under sexual reproduction, random mating and little or no selection. For those populations showing clonal variation for infection, the fixation index was more negative (indicating heterozygote excess), and the GDR lower, than in those populations not showing clonal variation for infection. A fixation index that deviates from 0.0 or a GDR significantly lower than 1.0 indicates that genotypic diversity has been withered by clonal selection (or, less likely, genetic drift) and that recombination was not frequent enough to restore equilibrium conditions.

Thus, the link between clonal variation for infection and the occurrence of genetic disequilibria is due either to among-population variation in the strength of selection, variation in the frequency of sex, or some combination of both. The degree to which variation in the GDR is due to variation in selection pressure underlies an unknown amount of autocorrelation in Fig. 1, because the $X$-axis, a measure of clonal variation for infection, is likely also influenced by selection. The role of selection is difficult to elucidate from our population genetic data. However, some lines of evidence suggest that variation in selection pressure does not explain much of the variation among populations and species of this study. For example, parasite prevalence (though this does not explicitly describe selection pressure) did not differ between those populations that showed clonal variation for resistance and those that did not. Moreover, parasite prevalences did not differ among species, and there is no reason to suspect differences in average virulence between those parasites common on the three study species. For species of $D$. longispina and $D$. pulex, average fecundity of parasitized females was approximately $50 \%$ of that in healthy females (Little \& Ebert, 1999). The most common parasite of D. magna that we analysed (occurring in 8 of 17 populations) was the castrating bacterium Pasteuria ramosa, which reduces host fecundity by up to $100 \%$ in the field and in the laboratory (Ebert et al., 
1998). Another parasite common in our study of D. magna, White Bacterial Disease, reduces lifespan to a few days (Ebert, unpublished), whereas the common microsporidian (found in 7 of 17 populations) reduces fecundity by approximately one-third (unpublished data). If anything, D. magna, the species for which we had the least success in detecting clonal variation for infection, suffers under greater pressure from parasites (e.g. Stirnadel \& Ebert, 1997), and sample sizes of D. magna $($ average $N$ infected $=92$, healthy $=112$ ) were about double what they than in our analyses of the other two species (average $N$ infected $=56$, healthy $=66$ ), suggesting that power to detect clonal variation for infection was greater for D. magna.

Thus, although we cannot rule out the role of selection in explaining differences among populations or among the three study species, it seems plausible that variation in the level of sexual recruitment has largely mediated the incidence of genetic disequilibria and variation in the GDR. The key role played by the breeding system in determining the occurrence of genetic disequilibria has been extensively documented: the low GDR values found in populations where clonal variation for infection was detected are typical of obligate parthenogens (e.g. Little \& Hebert, 1994) or cyclical parthenogens known to have little or no sexual recruitment (Hebert, 1974a,b; Hebert et al., 1988), but very atypical of populations known to have frequent sexual recruitment. The frequency of sexual recruitment in Daphnia populations is mediated by habitat stability; intermittent ponds necessarily have frequent sexual recruitment from the sexually produced resting eggs, whereas permanent ponds may experience long-term clonal reproduction (Hebert, 1974a,b; Lynch, 1983). Populations showing clonal variation for infection in our studies might thus be of the permanent variety, where long-term clonal selection has reduced the population to just a few clones with discrete resistance characteristics that are linked to allozyme loci. As an aside, it may be that the outcome of long-term clonal selection differs for different traits. For example, Lynch's (1983) study of life history variation indicated that long-term clonal selection removes all but a few generalist genotypes. As theoretical studies suggest that selection by parasites will proceed in a frequency-dependent fashion that maintains polymorphism at resistance loci (Hamilton, 1980; Hamilton et al., 1990), generalist strategies may not be expected for resistance traits.

If variation in the intensity of parasite effects is not sufficient to explain the present results, but, instead, most variation in the occurrence of clonal variation for infection is due to variation in the frequency of sexual recombination, this has important implications for what our work says about the generality of resistance vari- ation in the wild. It implies that the detection of associations between allozymes and infection, an approach which relies on linkage disequilibrium, is less constrained by the existence of resistance variation than by the external factors (habitat permanency) which mediate the frequency of recombination. By this reasoning, the prevalence of genetic variation for resistance has been underestimated in our studies because those populations lacking associations between allozymes and infection had levels of sexual recruitment too high to permit the build-up of linkage. As linkage limits the ability of clones to respond to different forces of selection, clones are likely to respond only to predominate selective agents (Roy, 1998). Thus, the observation that the outcome of clonal selection seems to frequently involve clonal variation for infectivity indicates that selection on resistance phenotypes is common in Daphnia populations.

\section{Acknowledgements}

We thank Achim Carius, Jürgen Hottinger, Larry Weider, Fritz Nehrhoff von Holderberg and Gerhard Augustin for their assistance during data collection and/ or analysis. This work was supported by a Swiss-NF grant no. 31-39480.93 to DE and by a SANW Reisestipendium from the ETH, Zürich to TJL. Comments by Bitty Roy, Andrew Read and Wolfgang Weißer improved the quality of the manuscript.

\section{References}

BURDON, J. J. AND JAROSZ, A. M. 1991. Host-pathogen interactions in natural populations of Linum marginale and Melampsora lini. I. Patterns of resistance and racial variation in a large host population. Evolution, 45, 205-217.

CARVALHO, G. R. AND CRISP, D. J. 1987. The clonal ecology of Daphnia magna (Crustacea: Cladocera). I. Temporal changes in the clonal structure of a natural population. J. Anim. Ecol., 56, 453-468.

CHABoudez, P. AND BuRdon, J. J. 1995. Frequency-dependent selection in a wild plant-pathogen system. Oecologia, 102, 490-493.

DYBDAHL, M. F. AND LIVELY, C. M. 1995. Host-parasite interactions: Infection of common clones in natural populations of a freshwater snail (Potamopyrgus antipodarum). Proc. $R$. Soc. B, 260, 99-103.

EBERT, D., ZSCHOKKE-ROHRINGER, C. D. AND CARIUS, H. J. 1998. Within- and between-population variation for resistance of Daphnia magna to the bacterial endoparasite Pasteuria ramosa. Proc. R. Soc. B, 265, 2127-2134.

FRANK, S. A. 1996a. Problems inferring the specificity of plantpathogen genetics. Evol. Ecol., 10, 323-325.

FRANK, S. A. 1996b. Statistical properties of polymorphism in host-parasite genetics. Evol. Ecol., 10, 307-317. 
FRASER, B. D. 1972. Population dynamics and recognition of biotypes in the pea aphid. Can. Ent., 104, 1729-1733.

GROSHOLZ, E. D. 1994. The effects of host genotype and spatial distribution on trematode parasitism in a bivalve population. Evolution, 48, 1514-1524.

HALDANE, J. B. S. 1949. Disease and evolution. Supplemento a La Anno, 19, 68-75.

HAMilton, w. D. 1980. Sex versus non-sex versus parasite. Oikos, 35, 282-290.

HAMILTON, W. D. 1993. Haploid dynamic polymorphism in a host with matching parasites: effects of mutations/subdivision, linkage, and patterns of selection. J. Hered., 84, 328-338.

HAMilton, w. D., AXelrod, R. AND TANESE, R. 1990. Sexual reproduction as an adaptation to resist parasites. Proc. Natl. Acad. Sci. U.S.A., 87, 3566-3573.

HEBERT, P. D. N. 1974a. Ecological differences between genotypes in a natural population of Daphnia magna. Heredity, 33, 327-337.

HEBERT, P. D. N. 1974b. Enzyme variability in natural populations of Daphnia magna. II. Genotypic frequencies in permanent populations. Genetics, 77, 323-334.

HEBERT, P. D. N. AND BEATON, M. J. 1993. Methodologies for Allozyme Analysis Using Cellulose Acetate Electrophoresis. Helena Laboratories, Beaumont, TX.

HEBERT, P. D. N. AND WARD, R. D. 1976. Enzyme variability in natural populations of Daphnia magna. IV. Ecological differentiation and frequency changes of genotypes at Audley End. Heredity, 36, 331-341.

HEBERT, P. D. N., WARD, R. D. AND WEIDER, L. J. 1988. Clonaldiversity patterns and breeding-system variation in Daphnia pulex, an asexual-sexual complex. Evolution, 42, 147-159.

HOFFMANN, R. J. 1986. Variations in contributions of asexual reproduction to the genetic structure of populations of the sea anemone Metridium senile. Evolution, 40, 357-365.

INNES, D. J., SCHWARTZ, S. S. AND HEBERT, P. D. N. 1986. Genotypic diversity and variation in mode of reproduction among populations in the Daphnia pulex group. Heredity, 57, 345-355.

JAENIKE, J. 1978. A hypothesis to account for the maintenance of sex within populations. Evol. Theory, 3, 191-194.

JAROSZ, A. M. AND BURDON, J. J. 1991. Host-pathogen interactions in natural populations of Linum marginale and Melampsora lini: II. Local and regional variation in patterns of resistance and racial structure. Evolution, 45, 1618-1627.

KING, C. E. 1972. Adaptation of rotifers to seasonal variation. Ecology, 53, 408-418.

KREBS, C. J. 1989. Ecological Methodology. Harper \& Row, New York.
LEVIN, D. 1975. Pest pressure and recombination systems in plants. Am. Nat., 109, 437-451.

LitTLE, T. J. AND EBERT, D. 1999. Associations between parasitism and host genotype in natural populations of Daphnia (Crustacea: Cladocera). J. Anim. Ecol., 67, 134-149.

LITTLE, T. J. AND HEBERT, P. D. N. 1994. Abundant asexuality in tropical freshwater ostracodes. Heredity, 73, 549-555.

LYNCH, M. 1983. Ecological genetics of Daphnia pulex. Evolution, 37, 358-374.

LYNCH, M. AND DENG, H.-W. 1994. Genetic slippage in response to sex. Am. Nat., 144, 242-261.

PARKER, M. A. 1988. Disequilibrium between disease-resistance variants and allozyme loci in an annual legume. Evolution, 42, 239-247.

PARKer, M. A. 1994. Pathogens and sex in plants. Evol. Ecol., 8, 560-584.

PARKER, M. A. 1996. The nature of plant-parasite specificity. Evol. Ecol., 10, 319-322.

PIELOU, E. C. 1969. The measurement of diversity in different types of biological collections. Theor. Biol., 13, 131-144.

RICE, W. R. 1989. Analyzing tables of statistical tests. Evolution, 43, 223-225.

ROY, B. A. 1993. Patterns of rust infection as a function of host genetic diversity in natural populations of the apomictic crucifer, Arabis holboellii. Evolution, 47, 111-124.

ROY, B. A. 1998. Differentiating the effects of origin and frequency in reciprocal transplant experiments used to test negative frequency-dependent selection hypothesis. Oecologia, 115, 73-83.

ROY, B. A. AND BIERZYCHUDEK, P. 1993. The potential for rust infection to cause natural selection in apomictic Arabis holboellii (Brassicaceae). Oecologia, 95, 533-541.

SAS INSTITUTE INC. 1990. SAS/stAT. Version 6.06. SAS Institute Inc., Cary, NC.

SiMPSON, E. H. 1949. Measurement of diversity. Nature, 163, 668.

STIRNADEL, H. A. AND EBERT, D. 1997. The ecology of three Daphnia species - their microparasites and epibionts. J. Anim. Ecol., 66, 212-222.

SWOFFORD, D. L. AND SELANDER, R. B. 1988. BIOSYS-I. $A$ computer program for the analysis of allelic variation in population genetics and biochemical systematics. Release 1.7. Illinois Natural History Survey, Champaign, IL.

THOMPSON, J. N. AND BURDON, J. J. 1992. Gene-for-gene coevolution between plants and parasites. Nature, 360, 121-125.

WeBSTER, J. P. AND woolhouse, M. E. J. 1998. Selection and strain specificity. 